\section{Abstracts Invited for Second International Symposium on Infection Control}

\section{Dear Colleague:}

I am writing from London to encourage your attendance at the forthcoming Second International Symposium on Infection Control in Hospitals in August. As a result of my spending a sabbatical year here, I have had the opportunity to visit many parts of this exciting city and to appreciate its importance in the history of infectious diseases and infection control. Furthermore, there is a very active Hospital Infection Society and Infection Control Nurses' Society in the United Kingdom.

As of late January, we have received more than 100 abstracts from outside the United States, and several requests were made for deadline extension. We have complied with these requests and would ask that you also consider submitting an abstract. Abstract forms and travel information are available by calling the Infection Control Program Coordinator, Garber Travel at 800-225-4570 (in MA, 617-787-0600).
It is my hope that the international exchange will be interesting scientifically and also lead to lasting friendships.

Richard P. Wenzel, MD

Editor

\section{Cordis Ventricle Drainage-System: Open or Closed}

\section{To the Editor:}

The nursing personnel of the neurosurgical intensive care unit of the University Hospital, Freiburg, Federal Republic of Germany, noticed on several occasions that cerebral spinal fluid (CSF) leaked from the drip chamber of the Cordis VentricleDrainage System when placed horizontally. Although the drip chamber should be kept in an upright position, this is not always possible during the normal course of nursing routine (repositioning the patient, transport, etc.). In order to determine whether bacteria could enter the system from the outer surface of the so-called "hydrophobic bacterial filter" (as claimed by the manufacturer), the fol- lowing experiment was performed:

1. The system was filled with MuellerHinton broth.

2. The outer surface of the "hydrophobic bacterial air filter" was contaminated $5 \mu \mathrm{l}$ of an overnight culture of $S$. aureus $\left(1.3 \times 10^{4}-5 \times\right.$

3. The drip chamber was tilted $90^{\circ}(5$ $\min$ ).

4. The upright drip chamber was incubated for $24 \mathrm{~h}$ at $37^{\circ} \mathrm{C}$.

In five independent experiments the test strain was isolated from the broth in the system.

These results demonstrate that the so-called "hydrophobic bacterial air filter" is neither hydrophobic nor does it function as a bacterial filter. This malfunction probably explains why we isolated $P$. aeruginosa and other microorganisms repeatedly from the CSF of neurosurgical patients a few days after using the system. This serious shortcoming of a drainage system, which should be a closed instead of an open one needs to be corrected.

E. Gilsbach, MD F. Daschner, MD H. Habel

Departments of Neurosurgery and Hospital Epidemiology University Hospital Freiburg Federal Republic of Germany

\title{
CALL FOR ABSTRACTS
}

Abstracts are invited for presentation at the Second International Symposium on Infection Control in Hospitals, to be held in Kensington, London, England from August 11 to 15, 1986.

The symposium has been designed to attract a wide range of delegates, from many aspects of medicine, but all involved in infection control in hospitals: hospital infection control physicians and nurses, epidemiologists and public health authorities, microbiologists, and physicians concerned with immunosuppressed hosts.

Abstracts, papers, and posters will be considered for presentation.

An abstract form and program participation card may be obtained from:

Infection Control Program Coordinator

Garber Travel

P.O. Box 404 - Dept. 91-6025

Brookline, MA 02146

800-225-4570 (toll-free)

617-787-0600 (in Mass.) 